\title{
KẾT QUẢ CHUYỂN HAI VÀ BA PHÔI TẠI TRUNG TÂM HỖ TRợ SINH SẢN QUỐC GIA
}

\section{TÓM TẮT}

Mục tiêu: Trong thụ tinh ống nghiệm, phương pháp chuyển nhiều phôi một lần làm tăng tử lệ đa thai. Đa thai có tỳ lệ kết cục xấu của me và thai nhi. Nhằm hạn chế rủi ro này, đề tài nghiển cứu nhằm chọn lựa phương pháp chuyển số phôi phù hợp nhất, cập nhật theo sự phát triển ở các nước tiên tiến với mục tiểu: "Mô tả đặc điểm lâm sàng, cận lâm sàng, kết quả thai nghén của những phụ nữ dưới 35 tuối được thụ tinh trong ống nghiệm chuyển phôi 2 và 3 phổi nhẳm lựa chọn chuyển phôi an toàn, hiệu quả". Đối tượng và phương pháp: 495 trường hợp (250 chuyển 02 phôi và 245 chuyển 03 phôi đủ các tiêu chuẩn. Nghiên cứu mô tả đặc điểm lâm sàng, cận lâm sàng, kết quả kích thích buổng trứng, kết quả chuyển phôi, kết cục thai nghén. Kết quả: Tỷ lệ có thai sinh sống của nhóm chuyển 2 phôi là $35,2 \%$ và nhóm chuyển 3 phôi là $41,2 \%$. Tỷ lệ đa thai của nhóm chuyển 2 phôi là $6 \%$ và nhóm chuyển 3 phôi là $17,1 \%$. Chuyển 3 phôi làm tăng gấp 3,24 lần nguy cơ đa thai, gấp 2 lần nguy cơ đẻ non so với chuyển 2 phôi. Kết luận: Lựa chọn chuyển 2 phôi có hiệu quả và an toàn hởn chuyển 3 phôi.

Tư khoá: Thụ tinh ống nghiệm (TTTON), chuyển phôi, đa thai, đẻ non.

\section{SUMMARY}

\section{RESULTS OF TRANSFERRING 2 EMBRYOS} AND 3 EMBRYOS AT NATIONAL IVF CENTER

Background: In cycles of in vitro fertilization, transferring multiple embryo transfer may increase the risk of multiple gestations which can lead to several complications for both mother and child. In order to reduce the risk, we wanted to study whether increasing the number of embryos transferred would significantly boots the live birth rate of the patients. This article aims to describe the clinical characteristics, IVF's result and pregnancy rates of the women under 35 years old in fresh cycles, who underwent 2 and 3 embryos transfer. Subjects and methods: 495 cases ( 250 cases who transferred 2 embryos and 245 cases who transferred 3 embryos). We study patient's characteristic, blood test, IVF's result and pregnancy outcome. Results: the live birth rate of group with 2 and 3 embryos transfer was $35,2 \%$ and $41.2 \%$, relatively $(p=0.17)$. The multiple gestation rate of 3 embryos transfer's group is significantly higher than the group which transfer 2 embryos $(17,1 \%$ and $6 \%$, $p=0.0001)$. Transferring 3 embryos increase both

*Bệnh viện Phụ sản Trung ương Chịu trách nhiệm chính: Bùi Bảo Lâm Email: buibaolam1991@gmail.com Ngày nhận bài: 29/12/2021

Ngày phản biện khoa học: 25/1/2021 Ngày duyệt bài: 23/2/202

\section{Bùi Bảo Lâm*, Nguyễn Viết Tiến*}

the risk of multiple gestation and the risk of premature birth than transferring 2 embryos. Results: Transferring 2 embryos is safer than 3 embryos with the same pregnancy outcome.

Keywords: In vitro fertilization (IVF), multiple gestations, premature.

\section{I. ĐẶT VẤN ĐỀ}

Tỷ lệ thành công của các trung tâm thụ tinh ống nghiệm hàng đầu trên thế giới hiện nay vào khoảng 40\%[1]. Một trong những lý do đạt được tỷ lệ này là do chuyển nhiều phôi trong một lần chuyển. Phương pháp này làm tăng tỷ lệ đa thai và dẫn tới các kết cục xấu của me và thai.

Để hạn chễ vấn đề này, trên thế giới hiện nay đang dần thay đổi từ chuyển nhiều phôi sang chuyển 1 hoặc 2 phôi trong 1 chu kỳ. Do tỷ lệ thành công của việc chuyển từ 1 tới 2 phôi mỗi chu kỳ không có sự khác biệt nhiều so với chuyển 3 phôi mỗi chu kỳ [2] nên chúng tôi thực hiện đề tài này nhằm mục tiêu: Mô tả đặc điểm lâm sàng, cận lâm sàng, kết quả thai nghén của những phụ nữ dưới 35 tuổi được thụ tinh trong ống nghiệm chuyển phôi 2 và 3 phồi nhằm lựa chọn chuyển phôi an toàn hiệu quả.

\section{II. ĐỐI TƯƠ'NG VÀ PHƯƠ'NG PHÁP NGHIÊN CỨU}

2.1. Đối tượng: Có 495 trường hợp (250 chuyển 02 phôi và 245 chuyển 3 phôi) đủ các tiêu chuẩn:

Nữ được TTTON tuổi < 35. Các phôi chuyển là phôi ngày 3, tươi (có ít nhất 1 phôi chất lượng tốt). Loại các trường hợp: mang thai hộ, xin noãn, phôi đông lạnh, chuyển phôi không phải ngày 3. Nghiên cứu mô tả đặc điểm lâm sàng, cận lâm sàng, chuyển phôi và kết cục thai nghén.

\subsection{Các biến số nghiên cứu}

Bao gồm: Tuổi tại thời điểm kích thích buồng trứng, BMI, thời gian và loại vô sinh... Các xét nghiệm FSH, LH, Estradiol ngày 3 kỳ kinh, số lượng nang thứ cấp ngày 2 kỳ kinh... Tinh dịch đồ. Các chỉ số chu kỳ TTTON. Về kết quả thai nghén, đa thai, sinh non, tỷ lệ thai sinh sống...

2.3. Xử lý số liệu. Xử lý số liệu theo chương trình SPSS 20.0, test "Khi" bình phương $\left(\chi^{2}\right)$, TStudent test. Phân tích hồi quy nhị phân Binary Logistic để tính mối tương quan giữa tỷ lệ có thai lâm sàng, tỷ lệ thai sinh sống, tỷ lệ đa thai và tỷ lệ sinh non với số phôi chuyển. Sự khác biệt có ý nghĩa thống kê khi $p<0,05$. 


\section{KẾT QUẢ NGHIÊN CứU}

3.1. Một số đặc điểm và yếu tố liên quan vô sinh nữ. Vô sinh nguyên phát $(48,7 \%)$, thứ phát $254(51,3 \%)$. Tuổi trung bình nhóm chuyển 2 phôi là $29,26+3,4$, nhóm chuyển 3 phôi là $29,22+3,5$ năm $(p=0,88)$. Thời gian vô sinh trung bình nhóm chuyển 2 phôi là $4,17+2,5$ và nhóm 3 phôi là 4,39 $+2,8$ với $(p=0,37)$. Chỉ số BMI trung bình của các đối tượng là 19,8 +2,4 điểm trong giới han bình thường. Nguyên nhân vô sinh do vòi tử cung là thường gặp nhất với 204/495 trường hợp (41,2\%). Tinh trùng bất thường ít gặp nhất với 37/495 (7.5\%) và 4,5\% ở nhóm chuyển 3 phôi so với $10,4 \%$ nhóm chuyển 2 phôi). Rối loạn phóng noãn găp $9 \%$ ở nhóm chuyển 3 phôi và $13,2 \%$ ở nhóm 2 phôi. Các nguyên nhân khác có $14,2 \%$ ở nhóm chuyển 3 phôi so với 4,8\% nhóm chuyển 2 phôi. Không xác định được nguyên nhân ở nhóm chuyển 3 phôi và chuyển 2 phôi lần lượt là $39,2 \%$ và $22,4 \%$. Có 454/495 trường hợp kích thích buồng trứng lần đâu $(91,7 \%)$. Ớ cả hai nhóm kết quả về nồng độ FSH, LH, Estradiol trung bình khi kích thích buồng trứng trong giới hạn bình thường. Số nang thứ cấp trung bình của nhóm chuyển 2 phôi là 11,28 $+4,91$ nang, của nhóm chuyển 3 phôi là 10,63 + 5,14 nang với $(p=0,15)$. Nồng độ $A M H$ trung bình của nhóm chuyển 2 phôi là $3,86+$ $2,84 \mathrm{ng} / \mathrm{ml}$, cao hơn nhóm 3 phôi là $3,38+$ $2,1 \mathrm{ng} / \mathrm{ml}$. Sự khác biệt có ý nghĩa thống kê với $\mathrm{p}$
$=0,03$.

Về tổng liều FSH trung bình là 2190,35 + 827,05 IU (nhóm 2 phôi dùng nhiêuu hơn nhóm 3 phôi) với $\mathrm{p}=0,6$. Số noãn thu được sau chọc hút là $9,98+4,36$ noãn (ít nhất là 02 noãn/ bệnh nhân, nhiều nhất là 25 noãn). Số noãn $M$ II thu được là $8,26+4$ noãn. Không có sự khác biệt có ý nghĩa thống kê về số noãn MII trung bình giữa 2 nhóm chuyển 2 phôi và 3 phôi. Số phôi trung bình thu được ở nhóm 2 phôi là 6,46 $+3,98$ phôi, ít hơn nhóm 3 phôi có ý nghĩa thống kê với $p=0,04$. Tỷ lê thụ tinh trung bình nhóm 3 phôi là $86,17+15 \%$, cao hơn nhóm 2 phôi. Sự khác biệt này có ý nghĩa thống kê với $p$ $<0,01$. Dày niêm mạc tử cung là $11,27+2 \mathrm{~mm}$, không có sự khác biệt có ý nghĩa thống kê giữa 2 nhóm chuyển 2 và 3 phôi. Nồng đô Progesterone ngày tiêm hCG nhóm chuyển 2 phôi là $2,1+1,2 \mathrm{nmol} / \mathrm{L}$; nhóm chuyển 3 phôi là $2,4+0,9 \mathrm{nmol} / \mathrm{L}$. Nồng độ Progesterone trung bình nhóm 2 phôi thấp hơn nhóm 3 phôi. Sự khác biệt có ý nghĩa thống kê với $p=0,01$.

\subsection{Kết quả có thai}

3.2.1. Kết quả có thai theo số phôi chuyên. Có tổng cộng 1235 phôi được chuyển. Số túi thai quan sát được là 253 túi thai. Tỷ lệ làm tổ trung bình là $18,96+27,7 \%$, ở nhóm chuyển 2 phôi là $16,2+29,1 \%$, ở nhóm chuyển 3 phôi là $21,8+25,9 \%$, sư khác biêt có ý nghĩa thống kê với $p=0,025$ (Bảng 3.1).

Bảng 3.1. Kết quả có thai theo số phôi chuyển

\begin{tabular}{|c|c|c|c|c|c|}
\hline \multirow{2}{*}{ Chỉ số $\quad$ Số phôi chuyển } & \multicolumn{2}{|c|}{$\begin{array}{l}\text { Nhóm chuyển } 2 \\
\text { phối }(N=250)\end{array}$} & \multicolumn{2}{|c|}{$\begin{array}{c}\text { Nhóm chuyển } 3 \text { phôi } \\
(N=245)\end{array}$} & \multirow{2}{*}{$\begin{array}{c}\text { Tổng } \\
(\mathrm{p})\end{array}$} \\
\hline & $\%$ & $\mathbf{n}$ & $\%$ & $n$ & \\
\hline Tỷ lệ có beta hCG sau chuyến phôi & $39,6 \%$ & $(99 / 250)$ & $53,5 \%$ & $(131 / 245)$ & 0,001 \\
\hline Tý lệ có thai lâm sàng & $38 \%$ & $(95 / 250)$ & $49 \%$ & $(120 / 245)$ & 0,014 \\
\hline Tý lê đa thai & $6 \%$ & $(15 / 250)$ & $17,1 \%$ & $(42 / 245)$ & 0,0001 \\
\hline Tỳ lệ sảy thai & $0,4 \%$ & $(1 / 250)$ & $1,2 \%$ & $(3 / 245)$ & 0,3 \\
\hline Tỷ lệ thai ngoài tử cung & $0 \%$ & $(0 / 250)$ & $3,5 \%$ & $(7 / 245)$ & 0,2 \\
\hline Tỷ lê thai lưu & $2,8 \%$ & $(7 / 250)$ & $9,4 \%$ & $(23 / 245)$ & 0,002 \\
\hline Tỷ lệ sinh r & $5,6 \%$ & $(14 / 250)$ & $11,02 \%$ & $(27 / 24$ & 0,0001 \\
\hline Tỷ lế thai sinh sống & $35,2 \%$ & $(88 / 250)$ & $41,22 \%$ & $(101 / 245)$ & 0,168 \\
\hline Tỷ lề làm tố trung bình & 16,2 & 29,1 & & $+25,9$ & 0,025 \\
\hline
\end{tabular}

Tỷ lệ BN có beta hCG sau chuyển phôi của nhóm chuyển 2 phôi là $39,6 \%$, của nhóm 3 phôi là 53,5\%. Sự khác biệt có ý nghĩa thống kê $\left(\chi^{2}=\right.$ $9,6$ và $\mathrm{p}=0,001)$. Tỷ lệ có thai lâm sàng của nhóm chuyển 2 phôi là $38 \%$, của nhóm 3 phôi là $49 \%$, sự khác biệt có ý nghĩa thống kê $\left(\chi^{2}=6,1\right.$ và $p=0,014)$. Tỷ lệ đa thai của nhóm chuyển 3 phôi cao hơn nhóm chuyển 2 phôi $(17,1 \%$ và $6 \%)$, khác biệt có ý nghĩa thống kê ( $\chi^{2}=15$ và $p=0,0001)$. Có $1 / 250$ trường hợp sảy thai trong nhóm chuyển 2 phôi và $3 / 245$ ở nhóm chuyển 3 phôi. Tỷ lệ sảy thai là $0,8 \%$. Không có trường hợp chửa ngoài tử cung nào trong nhóm chuyển 02 phôi. Có 07 trường hợp chửa ngoài tử cung trong nhóm chuyển 03 phôi. Tỷ lệ thai ngoài tử cung là $1,4 \%$. Tỷ lệ thai lưu ở nhóm chuyển 2 phôi là $2,8 \%$ (7/250 trường hợp), thấp hơn nhóm chuyển 3 phôi $(9,4 \%, 23 / 245$ trường hợp). Sự khác biệt này có ý nghĩa thống kê $\left(\chi^{2}=9,4\right.$ và $\mathrm{p}=0,002)$. Tỷ lệ sinh non là $7,7 \%$. Tỷ lệ sinh 
non ở nhóm chuyển 3 phôi $(11,02 \%, 24 / 245$ trường hợp) cao hơn so với nhóm chuyển 2 phôi (5,6\%, 14/250 trường hợp). Sự khác biệt có ý nghĩa thống kê với $\chi^{2}=4,7$ và $\mathrm{p}=0,03$. Tỷ lệ thai sinh sống là $38,2 \%$. Tỷ lệ thai sinh sống của nhóm chuyển 2 phôi là $35,2 \%$. Tỷ lệ thai sinh sống của nhóm chuyển 3 phôi là 41,22\%. Không có sự khác biệt có ý nghĩa thống kê về tỷ lệ có thai sinh sống giữa 2 nhóm.

3.2.2. Đánh giá môî tương quan giữa kêt quả có thai và số phôi chuyển. Tăng số phôi chuyển từ 2 phôi lên 3 phôi làm tăng khả năng có beta hCG sau chuyển phôi lên 1,75 lần. Sự khác biệt có ý nghĩa thống kê với $p=0,002$. Khả năng dự đoán chính xác là $53,5 \%$. Tăng số phôi chuyển từ 2 phôi lên 3 phôi làm tăng khả năng có thai lâm sàng lên 1,56 lần. Sự khác biệt có ý nghĩa thống kê với $p=0,014$. Với khả năng dự đoán chính xác là $56,6 \%$. Tăng số phôi chuyển từ 2 phôi lên 3 phôi làm tăng khả năng có thai lâm sàng lên 1,3 lần. Sự khác biệt không có ý nghĩa thống kê với $p=0,168$. Khả năng dự đoán chính xác là $61,8 \%$. Tăng số phôi chuyển từ 2 phôi lên 3 phôi làm tăng nguy cơ đa thai lên 3,2 lần. Sự khác biệt có ý nghĩa thống kê với $p=$ 0,0001 . Khả năng dự đoán chính xác là $88,5 \%$. Tăng số phôi chuyển từ 2 phôi lên 3 phôi làm tăng nguy cơ sinh non lên 2 lần. Sự khác biêt có ý nghĩa thống kê với $p=0,03$. Khả năng dự đoán chính xác là $91,7 \%$.

\section{BÀN LUÂ̂N}

4.1. Đặc điểm và một số chỉ số liên quan ở vô sinh nữ dưới 35 tuổi. Trong nghiên cứu của chúng tôi, vô sinh nguyên phát chiếm $48,7 \%$, thứ phát chiếm $51,3 \%$. Tuổi trung bình, thời gian vô sinh, Chỉ số BMI của đối tượng nghiên cứu, kết quả của nghiên cứu tương đồng hoăc không khác biệt nhiều với các tác giả trên thể giới như Masschaele và cộng sự (2012) [2,3], Martikainen [4], Ashrafi và cộng sự (2015)[3]. Về nguyên nhân vô sinh thường gặp là vòi tứ cung với $204 / 495$ (41,2\%. Ít gặp nhất là bất thường tinh trùng với $37 / 495(7,5 \%)$. Vô sinh không rõ nguyên nhân chiếm tỳ lệ tương đối cao $(30,7 \%)$. Đối chiếu với các nghiên cứu của Martikainen và cộng sự (2001) [4], Ashrafi (2015) [3]. thấy tỷ lệ này cao $(30,7 \%)$ so với $7,8 \%$ (Martikainen) và $15 \%$ (Ashrafi). Tại Việt Nam, tỷ lệ vô sinh do vòi tử cung ở nước ta còn chiếm tỷ lệ cao (41,2\%).

Về nồng độ $\mathrm{FSH}$, LH và Estradiol xét nghiệm vào ngày thứ 3 của chu kỳ kinh ở nhóm chuyển 2 phôi và 3 phôi không có sự khác biệt có ý nghĩa. Định lượng $\mathrm{AMH}$, nồng độ $\mathrm{AMH}$ thường không bị dao động trong chu kỳ kinh nguyệt nên độ chính xác cao hơn và tin cậy hơn các chỉ số FSH, LH, Estradiol. Giá trị bình thường của AMH là từ $2-6,8 \mathrm{ng} / \mathrm{ml}$. Nghiên cứu này, nồng độ AMH trung bình của nhóm chuyển 2 phôi là 3,86 $+2,84 \mathrm{ng} / \mathrm{ml}$ và nhóm chuyển 3 phôi là $3,38+$ $2,1 \mathrm{ng} / \mathrm{ml}$ đều trong giới hạn bình thường. Tuy nhiên nồng độ $A M H$ trung bình của của nhóm chuyển 2 phôi lớn hơn nhóm chuyển 3 phôi, sự khác biệt có ý nghĩa với $p=0,03$. Kết quả của chúng tôi cao hơn so với Vương Thị Ngọc Lan (2016) là $3,09+2,52 \mathrm{ng} / \mathrm{ml}$ và thấp hơn của Malek Mansour Aghssa và cộng sự (2015) là 4,2 $+2,3 \mathrm{ng} / \mathrm{ml}[5,8]$.

Tổng số nang thứ cấp trung bình trong nhóm chuyển 2 phôi là $11,28+4,91$ nang, của nhóm chuyển 3 phôi là $10,63+5,14$ nang. Sự khác biệt giữa 2 nhóm là không có ý nghĩa thống kê $(p=0,15)$. Số nang thứ cấp trung bình trong nghiên cứu thấp hơn của Jayaprakasan (2012) và Agarwal (2014).

Tồng liều FSH ở nhóm 2 phôi nhiều hơn ở nhóm 3 phôi $(2208,6+890,5$ UI so với $2171,7+$ 758,2 UI). Có sự khác biệt về AMH có ý nghĩa giữa 2 nhóm chuyển 2 và 3 phôi nhưng đa số chì số $\mathrm{AMH}$ của bênh nhân trong giới han bình thường $(60 \%)$ nên ít ảnh hưởng tới tổng liêu FSH. Tổng liểu FSH sử dụng không có sự khác biệt giữa 2 nhóm chuyển 2 và 3 phôi.

Tổng số noãn thu được là 4939 noãn. Trong đó nhóm chuyển 2 phôi là 2593 noãn $(52,5 \%)$, nhóm chuyển 3 phôi là 2346 noãn (47,5\%).

Số noãn trung bình thu được là $9,98+4,36$ noãn. Bệnh nhân có số noãn ít nhất là 02 (AMH: $0,2 \mathrm{ng} / \mathrm{ml})$, nhiều nhất là 25 noãn (AMH: 15 $\mathrm{ng} / \mathrm{ml}$ ). Số noãn trung bình của nhóm chuyển 2 phôi nhiều hơn so với nhóm chuyển 3 phôi. Sự khác biệt có ý nghĩa thống kê $(p=0,04)$.

Tại Trung tâm Hỗ trợ sinh sản Quốc Gia, giai đoạn 2015-2019, đa số các trường hợp được chuyển 3 phôi. Chuyển 2 phôi thường là do nhu cầu và nguyện vọng hoặc đối tượng có nhiều phôi tốt. Sunkara (2011)[6] nghiên cứu phân tích gộp 400.135 chu kỳ thụ tinh trong ống nghiệm cho thấy số nang trung bình là 8 nang thì tỷ lệ thai sinh sống dao động từ 11\%-34\%. Nghiên cứu của chúng tôi có tỷ lệ thai sinh sống là $38,2 \%$ phù hợp với kết quả nghiên cứu trên. Số noãn MII trung bình của nhóm chuyển 02 phôi là $8,18+4,8$ noãn. Số noãn MII trung bình của nhóm chuyển 3 phôi là $8,33+3,0$ noãn. Không có sự khác biệt có ý nghĩa thống kê về số noãn MII thu được giữa nhóm chuyển 2 phôi và 
3 phôi. Kết quả nghiên cứu của chúng tôi cũng tương đồng với nghiên cứu của Ashrafi và đồng nghiệp (2015) [3].

Nghiên cứu này có tỷ lệ thụ tinh đạt $81,9 \%$. Tỷ lệ thụ tinh trung bình của nhóm chuyển 2 phôi là $80,2+18 \%$, của nhóm chuyển 3 phôi là $86,17+15 \%$. Tỷ lệ thụ tinh trung bình của nhóm chuyển 3 phôi cao hơn nhóm 2 phôi, sư khác biêt có ý nghĩa thống kê với $\mathrm{p}=0,01$. Theo Ashrafi và cộng sự (2015), tỷ lệ thụ tinh của nhóm chuyển 2 phôi là $61,5+30,5$ và nhóm chuyển 3 phôi là $61,2+35,0$ [3]; thấp hơn của chúng tôi.

4.2. Kết quả có thai. Tỷ lệ làm tổ của chúng tôi là 253 túi thai, nhóm chuyển 2 phôi là $16,2+29,1 \%$, nhóm chuyển 3 phôi là $21,8+$ $25,9 \%$. Tỷ lệ làm tổ ở nhóm chuyển 3 phôi cao hơn nhóm chuyển 2 phôi. Sự khác biệt có ý nghĩa $(p=0,025)$.

Bảng 4.1. So sánh tỷ lệ làm tổ theo số phôi chuyển giữa các nghiên cứu

\begin{tabular}{|c|c|c|c|c|}
\hline \multirow{2}{*}{ Nghiên cứu } & \multicolumn{2}{|c|}{ Ashrafi (2015) [3] $(p=0,07)$} & \multicolumn{2}{c|}{ Bùi Bảo Lâm (2020) $(p=0.025)$} \\
\cline { 2 - 5 } Chỉ số & $\begin{array}{c}\text { Nhóm chuyển } \\
2 \text { phôi }\end{array}$ & $\begin{array}{c}\text { Nhóm chuyển } 3 \\
\text { phôi }\end{array}$ & $\begin{array}{c}\text { Nhóm chuyển } 2 \\
\text { phôi }\end{array}$ & $\begin{array}{c}\text { Nhóm chuyển } 3 \\
\text { phôi }\end{array}$ \\
\hline Tỷ lệ làm tổ $(\%)$ & $26,1+35,7$ & $20,0+29,5$ & $16,2+29,1$ & $21,8+25,9$ \\
\hline
\end{tabular}

Kết quả nghiên cứu của chúng tôi ngược lại so với kết quả nghiên cứu của Ashrafi và cộng sự (2015) [3]. Sự khác biệt về kết quả giữa 2 nghiên cứu có thể nằm ở chiến lược chuyển số phôi.

4.2.1. Tỷ lệ có thai lâm sang. Tỷ lệ có thai lâm sàng là $43,43 \%$ (của nhóm chuyển 2 phôi là $38 \%$, nhóm chuyển 3 phôi là $49 \%$, có sự khác biệt có ý nghĩa $(p=0,025)$. Ngày nay trong quá trình làm thụ tinh ống nghiệm, người ta quan tâm nhiều tới tỷ lệ có thai sinh sống thay vì tỷ lê có thai lâm sàng.

4.2.2. Tỷ lệ đa thai, tỷ lệ sinh non và tỷ lê có thai sinh sống. Tỷ lê đa thai nói chung trong nghiên cứu của chúng tôi là $11,5 \%$. Tỷ lề đa thai của nhóm chuyển 2 phôi là $6 \%(15 / 250)$, nhóm chuyển 3 phôi là $17,1 \%$ (42/245 trường hợp), sự khác biệt có ý nghĩa $\mathrm{p}=0.0001$. Việc chuyển nhiều phổi sẽ làm tăng nguy cơ đa thai đã được nhiều tác giả trên thế giới nghiên cứu và đề cập tới trong thời gian gần đây $[2,3,4]$. Kết quả nghiên cứu của chúng tôi cũng phù hợp với các tác giả này.

Tỷ lệ sinh non nói chung trong nghiên cứu là $8,3 \%$. Tỷ lệ sinh non nhóm chuyển 2 phôi là $5,6 \%$, nhóm chuyển 3 phôi là $11,02 \%$, sư khác biệt có ý nghĩa $(p=0,0001)$. Như vậy tằng số phôi chuyển từ 2 lên 3 phôi sẽ làm tăng nguy cơ sinh non. Kết quả của chúng tôi cũng phù hợp với các tác giả khác trên thế giới $[2,3,4]$.

Tỷ lệ thai sinh sống là $38,2 \%$. Với nhóm chuyển 2 phôi là $35,2 \%$ và nhóm chuyển 3 phôi là $41,2 \%$. Sự khác biêt không có ý nghĩa ( $p=$ $0,17)$. Như vậy việc tăng số phôi chuyển từ 2 phôi lên 3 phổi không làm thay đổi tỷ lệ thai sinh sống. Một số tác giả khác trên thế giới cũng đã nghiên cứu về vấn đề này và có kết quả tương tự chúng tôi [3].

Không có chửa ngoài tử cung ở nhóm chuyển
02 phôi, có 07 trường hợp ở nhóm chuyển 03 phôi. Có 1 sảy thai (8 tuần) ở nhóm chuyển 2 phôi và 03 trường hợp ở nhóm chuyển 02 phôi $(12,15$ và 16 tuần).

Tỷ lệ thai lưu nhóm chuyển 2 phôi: 2,8\% (7/250 trường hợp), thấp hơn nhóm 3 phôi $(9,4 \%, 23 / 245)$. Khác biệt có ý nghĩa với $\chi^{2}=$ 9,4 và $\mathrm{p}=0,002$.

Việc tăng số phôi chuyển từ 2 lên 3 phôi dẫn đến có thai lâm sàng tăng lên 1,56 lần với dự đoán chính xác là $56,6 \%$. Nguy cơ đa thai tăng lên 3,24 lần với dự doán chính xác 88,5\%. Nguy cơ sinh non cũng tăng gấp 2 lần với dư đoán chính xác 91,7\%. Theo Ashrafi (2015)[3], việc chuyển 02 phôi làm tăng tỷ lệ thai sinh sống lển gấp 3,1 lần. Chúng tôi thây rằng việc tăng số phôi chuyển từ 2 phôi lên 3 phôi làm tăng nguy cơ đa thai và sinh non. Do đó cần có sự thay đổi về quan điểm thực hành lâm sàng là giảm số lượng phôi chuyển. Các nghiên cứu trên thế giới đang tiến hành nhằm giảm số lượng phôi chuyển để làm giảm các nguy cơ do đa thai, đăc biệt là sinh non $[2,3]$. Mỹ, Pháp, Canada... chuyển đơn phôi có chọn lọc đã và đang áp dụng rộng rãi [4]. Theo hiệp hội Nội tiết sinh sản và Hiếm muộn Canada, Hiệp hội thực hành Sản - Phu Khoa Canada [7,8], với những phu nữ dưới 35 tuổi được khuyến cáo không nên chuyển quá 2 phôi.

\section{KẾT LUÂN}

Thời gian vô sinh hay gặp là dưới 5 năm $(59,4 \%)$. Nguyên nhân vô sinh do vòi tử cung rất thường gặp (41,2 \%). Số nang thứ cấp trung bình của nhóm chuyển 2 phôi cao hơn nhóm chuyển 3 phôi. Số noãn trung bình sau chọc hút của nhóm chuyển 2 phôi nhiều hơn nhóm chuyển 3 phôi. Nồng độ progesterone ngày tiêm hCG trung bình của nhóm chuyển 3 phôi cao hơn 
nhóm chuyển 2 phôi. Nhóm chuyển 3 phôi có beta hCG sau chuyển phôi, tỷ lệ có thai lâm sàng, tỷ lệ đa thai, tỷ lệ sinh non, tỷ lệ thai lưu cao hơn nhóm chuyển 2 phôi. Không có sự khác biệt về tỷ lệ thai sinh sống giữa 2 nhóm chuyển 2 và 3 phôi. Chuyển 3 phôi làm tăng gấp 3,24 lần nguy cơ đa thai, gấp 2 lần nguy cơ đẻ non so với chuyển 2 phôi. Chuyển 2 phôi là lựa chọn hợp lý, an toàn và hiệu quả.

\section{TÀI LIẸU THAM KHẢO}

1. International Federation of Fertility Societies' Surveillance (IFFS) 2019: Global Trends in Reproductive Policy and Practice, 8th Edition. Global Reproductive Health. 2019;4(1):e29-e29

2. Masschaele T, Gerris J, Vandekerckhove F, De Sutter P. Does transferring three or more embryos make sense for a well-defined population of infertility patients undergoing IVF/ICSI? Facts Views Vis Obgyn. 2012;4(1):51-58

3. Ashrafi $M$, Madani $T$, Movahedi $M$, et al. Increasing The Number of Embryos Transferred from Two to Three, Does not Increase Pregnancy
Rates in Good Prognosis Patients. International journal of fertility \& sterility. 2015;9:292-299.

4. Martikainen $H$, Group the FES, Titinen A, et al. One versus two embryo transfer after IVF and ICSI: a randomized study. Hum Reprod. 2001;16(9):1900-1903.

5. Vương Thị Ngoc Lan. Giá trị các xét nghiêm $\mathrm{AMH}, \mathrm{FSH}$ và $\mathrm{AFC}$ dự đoán đáp ứng buồng trứng thụ tinh trong ống nghiệm. Đại học $Y$ dược thành phố Hồ Chí Minh.2016.

6. Sunkara SK, Rittenberg $\mathbf{V}$, Raine-Fenning $\mathbf{N}$, Bhattacharya S, Zamora J, Coomarasamy A. Association between the number of eggs and live birth in IVF treatment: an analysis of 400135 treatment cycles. Hum Reprod. 2011;26(7):1768-1774.

7. Taşdemir M, Taşdemir I, Kodama H, Fukuda J, Tanaka T. Implantation: Two instead of three embryo transfer in in-vitro fertilization. Hum Reprod. 1995; 10(8):2155-2158.

8. Min JK, Hughes E, Young D, Joint Sogc-Cfas Clinical Practice Guidelines Committee, Reproductive Endocrinology And Infertility Committee. Elective single embryo transfer following in vitro fertilization. J Obstet Gynaecol Can. 2010;32(4):363-377.

\section{ĐÁNH GIÁ HIỆU QUẢ ĐIỀU TRI GIẢM ĐAU BÊNNH NHÂN UNG THƯ DI CĂN XƯO'NG BẰNG XẠ TRI TẠI BỆNH VIỆn 198-Bộ CÔNG AN}

\section{Nguyễn Thị Minh Phương*, Hoàng Thanh Tuyền*, Nguyễn Minh Dũng*, Vi Thành Long*}

\section{TÓM TẮT}

30 bênh nhân ung thư di căn xương đau mức độ vừa hoặc nặng, được điều trị bằng thuốc giảm đau thông thường không hiệu quả. Chiếu xạ ngoài đạt hiêu quả giảm đau sau 1 tuần, giảm đau tốt sau 1 tháng, $20 \%$ hết đau hoàn toàn, $70 \%$ đáp ứng một phân, 10\% bênh không đáp ứng giảm đau. Giảm đau sau xạ trị có ý nghĩa thống kê ở tất cả các nhóm 1 vị trí tổn thương, > 1 vị trí tổn thương và có tổn thương kết hơp.

Từ khóa: Ung thư di căn xương, giảm đau, xạ trị

\section{SUMMARY}

\section{EFFECTS OF PALLIATIVE TREATMENT BY RADIATION IN CANCER PATIENTS WITH BONE METASTASES AT 198 HOSPITAL}

30 patients with pain (moderate or severe) due to bone metastase were treated by conventional analgesics drug but not effective. These patients were treated by radiation bone pain relief response last 1 week good response last 1 month, 20\% very good

*Bệnh viện 198, Bộ Công An

Chịu trách nhiệm chính: Nguyễn Thị Minh Phương

Email: drminhphuong198@gmail.com

Ngày nhận bài: 26/12/2021

Ngày phản biện khoa học: 28/1/2021

Ngày duyệt bài: 26/2/2021 response, $70 \%$ with partial response, $10 \%$ not response. Bone pain relief response in all group 1 tumor, $>1$ tumors and many tumors.

Keywords; Bone cancer, analgesics, radiation

\section{I. ĐĂT VẤN ĐỀ}

Ung thư có su hướng ngày càng gia tăng trong những thập niên gần đây, bệnh nhiều khi không có triệu chứng lâm sàng rõ rệt. Bệnh thường phát hiện khi đã ở giai đoạn muộn, có di căn xa. Tỷ lệ ung thư di căn xương chiếm từ 30$70 \%$ số bệnh nhân tùy theo loại ung thư và giai đoan bênh [5]. Ung thư di căn xương không những làm giảm thời gian sống của bênh nhân mà còn giảm chất lượng sống và gây các triệu chứng thường gặp như đau xương (xảy ra ở 2/3 bênh nhân có di căn xương). Điều trị giảm đau có vai trò quan trọng và cần thiết, nhằm cải thiện chất lượng sống cho người bệnh. Có nhiều phương pháp điêu trị giảm đau như: phẫu thuật, hóa trị, thuốc giảm đau, xạ trị...Mỗi phương pháp có tác dụng trong những trường hợp nhất định. Sử dụng thuốc giảm đau có tác dụng trong thời gian ngắn, nhiều tác dụng phụ khồng mong muốn, tình trạng nhờn thuốc khiến bênh nhân phải tăng liều... Điều trị giảm đau bằng xạ trị 